\title{
Retraction Note to: Simulation of rainfall process in mountainous regions and sports athletes' fatigue recovery based on convolutional neural network
}

\author{
Luo Liang $^{1} \cdot$ He Beina ${ }^{1}$
}

Published online: 9 November 2021

(c) Saudi Society for Geosciences 2021

Retraction Note to: Arabian Journal of Geosciences (2021) 14: 982

https://doi.org/10.1007/s12517-021-07364-0

The Editor-in-Chief and the Publisher have retracted this article because the content of this article is nonsensical. The peer review process was not carried out in accordance with the Publisher's peer review policy. Author He Beina has not responded to correspondence regarding this retraction. The publisher has not been able to obtain a current email address for author Luo Liang.

The original article can be found online at https://doi.org/10.1007/ s12517-021-07364-0.

He Beina

luogongzhi123456@163.com

1 Police Sport and Training Department, Hubei University of Police, Wuhan 430000, Hubei, China 